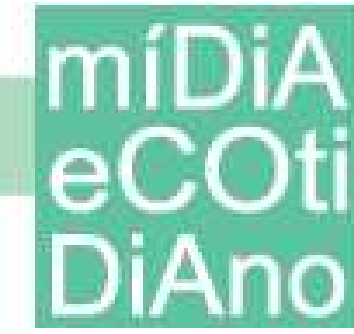

Revista Eletrônica do Programa de Pós-Graduação em Mídia e Cotidiano Artigos Seção Livre

Número 5. Dezembro/ 2014

(C) 2014 by UFF

\title{
UM OLHAR DA SEMIÓTICA DA CULTURA SOBRE JOGOS DIGITAIS E SEUS AVATARES
}

\section{A look at the semiotics of culture on digital games and their avatars}

\author{
Nísia Martins do ROSÁRIO ${ }^{1}$; Carlise DUARTE ${ }^{2}$; Lorena RISSE ${ }^{3}$
}

Resumo: O objetivo desse texto é abordar os jogos digitais e seus avatares a partir de um panorama oferecido pela semiótica da cultura. Buscando ampliar a compreensão sobre esses objetos por uma perspectiva da Escola de Tartu, sobretudo de Lotman, desenvolvemos uma reflexão sobre o campo semiótico que se configura nesse âmbito. Escolhemos três eixos principais para organizar o pensamento. Primeiro nos esforçamos em constituir uma perspectiva diacrônica do jogo, visando alcançar elementos fundantes desse sistema para entender as configurações assumidas por ele contemporaneamente. Por essa via, alcançamos o segundo eixo que procurou esboçar um desenho da semiosfera que envolve o jogo digital considerando sistemas, códigos, fronteiras, tradução. Por fim, nos detivemos nos avatares, suas modelizações e as semioses culturais.

Palavras-chave: semiótica da cultura; jogos digitais; avatares;

Abstract: The aim of this paper is to address the digital games and their avatars from a panorama offered by the semiotics of culture. Seeking to broaden the understanding of these objects from a perspective of the School of Tartu, especially Lotman, we want to develop a reflection on the semiotic field that is configured in that context. We chose

\footnotetext{
${ }^{1}$ Docente e pesquisadora da Universidade Federal do Rio Grande do Sul - UFRGS - no Programa de Pós Graduação Comunicação e Informação, bolsista PQ CNPq. Doutora em Comunicação Social pela PUC/RS. Integrante dos diretórios de pesquisa PROCESSOCOM e GPESC. E-mail: nisia@corporalidades.com.br

${ }^{2}$ Doutoranda em Comunicação e Informação pela UFRGS. Mestre em Ciências da Comunicação pela UNISINOS. Licenciada e Bacharel em Dança pela Faculdade de Artes do Paraná (FAP). E-mail: carlisesd@hotmail.com

${ }^{3}$ Mestrado em Comunicação e Informação pela UFRGS (2014) com apoio da Capes. Graduação em Jornalismo pela Unisinos (2012). Integrante do diretório de pesquisa GPESC. E-mail: lorenarisse@gmail.com
} 


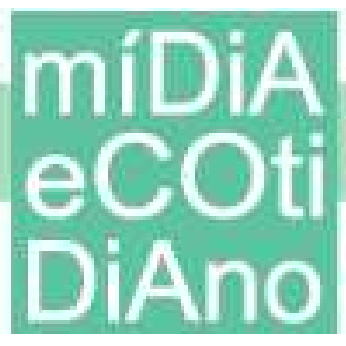

three main axes to organize the thinking. First we strive to provide a diachronic perspective of the game in order to achieve foundational elements of this system to understand the configurations assumed by him contemporaneously. By this way, we reach the second axis which sought to sketch a drawing of the semiosphere which involves the digital games considering systems, codes, frontiers and translations. Finally, we abode in the avatars, their modeling and the cultural semiosis.

Keywords: semiotics of culture; digital games; avatars;

\section{Introdução}

O conceito de cultura de Lotman $(2000,1999)$ compreende várias perspectivas e envolve os eixos principais de seus estudos: semiosfera, sistemas, linguagens, códigos, codificação, memória, fronteiras, tradução. Machado (2007: 58) consegue sintetizar afirmando que Lotman "formulou a noção de cultura como dispositivo pensante dotado, portanto de inteligência e memória, vale dizer, de ordenamento e de capacidade gerativa".

Nessa perspectiva, a cultura é compreendida como a combinação de vários sistemas de signos, cada um com codificação própria, que se estabelece na relação entre esses sistemas. Para Lotman (2000), a cultura é uma memória coletiva, na qual alguns textos comuns podem se conservar e se atualizar sob alguma invariante de sentido que permite identificá-los no contexto da nova época com todas as variadas interpretações. "A memória [...] é assegurada, em primeiro lugar, pela presença de alguns textos constantes e, em segundo lugar, pela unidade dos códigos ou por sua invariância ou pelo caráter ininterrupto e regular de sua transformação" (LOTMAN apud. VELHO, 2009: 2). Assim, a memória comum (informativa) de uma dada cultura é identificada pela presença de alguns textos que permanecem e pela unidade de códigos em seu caráter invariável e sua transformação regular. Essa memória informativa inclui os mecanismos aprendidos através de atividades cognitivas sobre uma determinada técnica, tais como os mecanismos de funcionamento do jogo digital. Existe também a memória criadora, responsável pela edificação de novos textos na cultura e própria da arte, pois está em 


\section{míDiA

potência e pode se atualizar nos textos, como no caso da criação de diversos formatos e narrativas para os jogos digitais. A atualização dos textos está subordinada às complexas leis do movimento cultural.

Cada cultura define su paradigma de qué se debe recordar (esto es, conservar) y qué se há de olvidar. Esto último es borrado de la memoria de la conectividade y es como si dejara de existir. Pero cambia el tempo, el sistema de códigos culturales, y cambia el paradigma de memoria olvidado. (LOTMAN, 2000: 160).

A estrutura dinâmica da memória da cultura se caracteriza por sua individualização, que só existe em certo nível onde possa ser reconhecida e supõe a presença de variáveis internas, responsáveis pela organização das conexões que constituem o sistema da cultura dada. Sabemos, contudo, que os sistemas não são compreendidos apenas pelo seu contexto diacrônico, mas também pela relação deste com seu eixo sincrônico, ou seja, pela conjugação de simultaneidade e de sucessões.

Para a abordagem proposta entendemos que, num primeiro momento, é importante nos atermos a considerações sobre o eixo diacrônico do jogo, as sucessões retidas pela memória coletiva, considerando aspectos que o constituem no território da cultura.

\section{Uma diacronia do Jogo}

A cultura do jogo é tão antiga quanto o homem e, assim como sofre atualizações e transformações regulares, opera com textos e códigos constantes, mais duráveis, que permitem a recuperação de seu substrato. A conservação dos textos nos sistemas é identificada pelos dois tipos de memórias explicados anteriormente: informativa e criadora.

Huizinga (1996) ${ }^{4}$ ressalta a função semiótica do jogo - ou seja, sua capacidade de produzir sentidos. Nessa via, discute importantes elementos articuladores da cultura do jogo que auxiliam a compreender os seus sistemas e codificações, tais como: a busca

\footnotetext{
${ }^{4}$ Huizinga foi um dos primeiros a propor um estudo sobre a relação entre jogo e cultura, que resultou na publicação de Homo Ludens, escrito em 1938, mas que traz muitos elementos importantes para sua compreensão e que podem ser percebidos na sociedade contemporânea.
} 


\section{míDiA

por prazer e divertimento; a irracionalidade, a tensão e a incerteza que o acompanham; a excitação advinda dessa prática. A noção de jogo por ele construída é a seguinte:

(...) o jogo é uma atividade ou ocupação voluntária, exercida dentro de certos e determinados limites de tempo e de espaço, segundo regras livremente consentidas, mas absolutamente obrigatórias, dotado de um fim em si mesmo, acompanhado de um sentimento de tensão e de alegria e de uma consciência de ser diferente da 'vida quotidiana' (HUIZINGA, 1996: 33).

Obviamente que, ao falar de jogo, não se pode ignorar a importância do elemento lúdico que o habita e o coloca em funcionamento. O jogo e o lúdico estão intimamente ligados, inclusive na sua origem etimológica ${ }^{5}$. A evolução do social, entretanto, "quer progredindo, quer regredindo" - como bem coloca Huizinga (1996: 54) -, ocultou o elemento lúdico sob uma cultura que absorveu e cristalizou muito mais o saber. Enquanto a herança racionalista minimiza a ousadia, o correr riscos, as incertezas e a tensão, a herança lúdica tende a maximizar esses elementos porque é justamente com eles que brinca. Assim, os jogos digitais retomam o lúdico no âmbito da cibercultura, afinal ele é traço essencial e importante nas sociedades humanas e precisa ser exercitado. Nesta perspectiva, os recursos tecnológicos permitem diferentes tipos dessa prática, por meio da interação sensório-motora, conforme o console em que são jogados.

Nessa via, Sato (2009) diz que jogar é um ato espontâneo e divertido, onde o indivíduo interage com os elementos do jogo, dentro de determinadas regras; realiza ações que tornam as experiências desafiadoras e intensas. O indivíduo busca superar

\footnotetext{
${ }^{5}$ Huizinga (2010) salienta que no latim a palavra ludere, de onde deriva ludens, é utilizada para o jogo teatral, no sentido de simulação e "não seriedade". A palavra lares ludentes significa dançar. Com a transformação das escolas que ensinavam latim para o uso das línguas naturais de cada país, a palavra ludus foi substituída por uma derivada jocus cujo sentido abrange um terreno vasto. Assim, em qualquer língua hoje encontramos a ideia de jogo ligada a livre escolha em participar, a incerteza do resultado, a tensão, a alternância de possibilidades de realização segundo uma dada ordem, a distrair-se, passar o tempo e praticar. A tese proposta por Huizinga sobre o conceito de jogo baseou-se numa pesquisa sobre as diferentes interpretações para a palavra jogo em várias línguas. A palavra jogar é interpretada como recreação, relaxamento, divertimento, passatempo, excursão, distração, deboche, ócio, preguiça, disponibilidade, brincadeira, imitação, representação, simulação, lançar, ganhar, competir, para designar jogos infantis e jogos de adivinhação. Também é associada ao riso, ao lúdico, ao fazer piadas, ao ilusório.
} 


\section{míDiA

desafios e aprende de forma lúdica os aspectos inerentes ao jogo e ao contexto sociocultural em que ele está inserido. Assim, ele provém do imaginário coletivo de uma sociedade, é intrínseco à sua cultura e diz muito a respeito da sociedade.

Caillois (1990) amplia as tratativas sobre esse tema, vê alguns pontos limitantes no pensamento de Huizinga, principalmente no que se refere ao jogo e sua associação com o interesse material. Enquanto Huizinga praticamente descarta a possibilidade do jogo estar associado a interesses materiais (dinheiro), Caillois (1990: 25) abre espaço em sua obra para esse aspecto. Afinal, para ele, “o jogo é ocasião de gasto total: de tempo, de energia, de engenho, de destreza e muitas vezes de dinheiro". Outro aspecto interessante, destacado por Caillois, é que mistério e simulação são chaves para ativar o jogo - para lançar o desafio -, mas ainda mais importantes são os componentes de ficção e divertimento.

Um breve levantamento dos traços do jogo na cultura permite notar que, mesmo se configurando como um sistema muito antigo, ele preserva elementos constantes, ainda que apresente um caráter ininterrupto e regular de transformação. Assim, a memória informativa do jogo na cultura tende a manter a sua função semiótica articuladora do lúdico, do divertimento, do espontâneo, do mistério, da simulação e da ficção, mesmo que o formato, o espaço e o modo de sua realização sejam outros. Esses elementos constantes são facilmente encontrados nos jogos digitais. No Wow (World of Warcraft), por exemplo, o jogador é transportado para um mundo medieval de ficção, onde tem que simular, por meio do avatar, um ser fantástico da Horda ou da Aliança; conforme vai jogando desvenda o mistério do mapa das cidades e continentes e outros enigmas, que o conduzem por uma trilha de ludicidade. Essa diversão tem mais de 9,6 milhões de jogadores, segundo a empresa que o criou Acti Blizzard ${ }^{6}$.

Buscando uma maneira de organizar sua reflexão sobre o jogo, Caillois elabora uma classificação, delimitando-o em quatro categorias fundamentais: de competição (Agon), de sorte (Alea), de simulacro (Mimicry) e de vertigem (Ilinx). Entendemos que as categorias fundamentais, apesar de terem sido elaboradas bem antes da existência dos

\footnotetext{
${ }^{6}$ http://wowgirl.com.br/2013/02/08/balanco-acti-blizzard-wow-com-9-6mi-assinantes/
} 


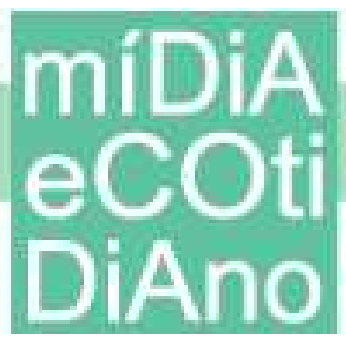

jogos digitais, são aplicáveis a eles considerando suas especificidades. Agon é a categoria da competição e do combate, dividido no tipo cerebral e no tipo muscular. Tecnicamente, os adversários devem se confrontar em condições ideais e com igualdade de oportunidades, ao mesmo tempo em que devem primar pela disciplina e perseverança. O objetivo dos participantes é ver reconhecida a sua excelência, como em jogos digitais de esportes, de habilidade artística e de guerra (exemplos: Fottball; Guitar Hero; Central Dance, World of war craft). Apesar da força física não ser uma exigência nesses casos ela é delegada ao avatar que representa o jogador.

O Alea é o jogo situado no lado oposto do Agon, pois trata de vencer o destino e não um adversário, portanto, independe das decisões do jogador. Esse, no jogo de Alea, conta exclusivamente com a sorte, ou com a benevolência do destino. Essa categoria nega o trabalho, a habilidade, a qualificação, o treino. É amplamente oferecido na internet em modalidades como dados, roleta, apostas. Agon e Alea, contudo, ajustam-se à mesma regra: a criação artificial de igualdade entre os parceiros.

Mimicry, por sua vez, articula-se sobre a ilusão ${ }^{7}$ temporária, sobre o imaginário, buscando ludibriar o jogador. Essa categoria consiste "na encarnação de um personagem ilusório e na adopção do respectivo comportamento" (CAILLOIS, 1990: 41), o que faz da mímica e do disfarce dois de seus aspectos fundamentais. Assim, Mimicry exige imaginação e interpretação. Um bom exemplo de como a Mimicry se apresenta nos jogos digitais são os de dança como o Michael Jackson- The experience (2010), para o console Xbox 360 com Kinect.

Ilinx, por fim, é a categoria que, por alguns momentos, desestabiliza a percepção, cria um pânico voluptuoso que se impõe à consciência lúcida. Por opção própria, o participante da Ilinx busca um atordoamento orgânico e psíquico. Segundo o autor, esse gosto pela vertigem pode estar associado ao gosto, reprimido, pela desordem e pela destruição. Resident Evil é um dos jogos digitais que permite o atordoamento psíquico.

\footnotetext{
${ }^{7}$ É interessante lembrar que Huizinga, ao trabalhar a noção do lúdico e sua origem etimológica, remete à ilusão através de in-ludio e de ludere.
} 


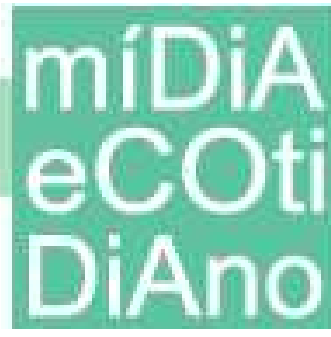

\section{A semiosfera do jogo digital}

Depois do longo predomínio da lógica, da razão e da ordem, as sociedades contemporâneas parecem estar articulando o seu processo comunicativo dando espaço para os laços emocionais e, nessa via, o lúdico ganha território. O processo que conduz à articulação dos grupos sociais coloca em cena o jogo: "no centro das atividades esportivas (...), está igualmente onipresente na eflorescência e na diversificação dos jogos de sociedade, mas, por um ardil bem compreensível, isso resulta no fato da própria sociedade se tornar jogo" (MAFESOLLI, 1990: 18)

As sociedades contemporâneas organizam-se sem considerar tanto os macrovalores e as macronarrativas e, sim, comungam valores minúsculos numa rede complexa, de contornos difusos e fluidos, e isso é o que parece dar força ao jogo nessas mesmas sociedades. Maffesoli (1990) entende que o espaço conquistado pelo afetual, bem como a rede de microvalores estabelecida pelas tribos e o narcisismo coletivo ajudam a delinear as sociedades, a estética e a ética contemporâneas. Nessa via, o jogo digital é merecedor de reconhecimento nas representações sociais e comunicativas, vincula-se à determinada ética e estética, refletindo o desejo pelo divertimento, pelo entretenimento, pelo estado imaginativo, próprios da sociedade contemporânea.

Um dos movimentos que ajudaram a configurar o cenário propício para os jogos digitais corresponde à consolidação de tecnologias cada vez mais avançadas. A cibercultura e as tecnologias são duas instâncias que proporcionaram a construção de uma paisagem contemporânea contornada por atravessamentos múltiplos e que têm uma forte influência sobre processos de subjetivação, que atingem não apenas os jogos digitais, mas o mundo digital como um todo. As transformações e as facilitações tecnológicas se materializaram na implementação de inúmeras mudanças tais como ferramentas de navegação e de escaneamento, recursos de interface para o melhor entendimento do usuário, qualidade de imagem. É interessante lembrar que os jogos digitais estabelecem um espaço diferenciado para o lúdico que, de maneira incomum coloca em ambientes distintos os jogadores, eliminando as características postas por Huizinga (1996) de aproximar (fisicamente) os participantes e de ser uma atividade 


\section{míiA

realizada ao ar livre. As tecnologias, entretanto, tentam articular facilidades de integração dos jogadores tornando os produtos cada vez mais sensoriais, e colocando em conexão usuários de espaços e em tempo igualmente diferenciados.

Santaella e Feitoza (2009) apresentam três tipos de jogos digitais: os de consoles de vídeo games, com visualização em monitores de televisão ou portáteis; jogos para computadores, conectados em rede ou não; jogos para árcades, que são máquinas integradas (console-monitor). Cada tipo de aparelho permite um tipo de interação mediada e proporciona diferentes experiências cognitivas.

As perspectivas trazidas até aqui atravessam o jogo digital e ajudam a compreendê-lo em seu contexto. Afinal, ele expressa um traço social, atravessa a vida cotidiana, é um dos formatos culturais e comunicacionais que tem deixado marcas nos comportamentos e posturas da sociedade. Para adentrar na sua semiosfera é preciso, contudo, saber mais sobre os seus sistemas, linguagens, códigos, semioses.

Lotman (2000) propõe o estudo da semiosfera para compreender o dispositivo pensante da cultura que permite a produção de semiose. Ou seja, um mecanismo pelo qual ocorre a edificação de mensagens no contexto das relações entre sistemas de signos. Assim, é possível afirmar que a semiosfera é uma dimensão de espaço-tempo em que se realizam os processos de significação e também os processos comunicativos. É o ambiente de produções de novas informações, atualização de códigos e de linguagens, organização de sistemas modelizantes, articulação de regularidades, repetições e legitimações, bem como de criações, irregularidades e desterritorializações. Assim, o conceito de semiosfera torna-se fundamental para entender os processos de tradutibilidade e semiose que ocorrem nas relações sistêmicas do jogo digital e nos corpos digitais dos avatares. Pode-se defender a existência de uma semiosfera própria do jogo, que se torna mais especifica quando das organizações e correlações dos jogos digitais.

Ao investigar os mecanismos que desencadeiam relações e conexões entre diferentes códigos culturais organizados em sistemas de signos, Lotman (2000) observou o ordenamento e constatou que alguns não correspondiam às ações previstas, então concluiu que a irregularidade e imprevisibilidade são os agentes das relações e da 


\section{míDiA

informação nova. Dessa maneira, ao mesmo tempo em que no espaço da semiosfera se identificam as regularidades e previsibilidades dos códigos e sistemas, também se observam as irregularidades, imprevisibilidades e assimetrias. As propriedades fundamentais dos códigos, dessa forma, são: a conservação e a mudança.

Conforme propõe Lotman (2000) a semiosfera é um espaço de relações resultante do diálogo que se estabelece entre diferentes sistemas. Os jogos digitais e seus avatares acionam pelo menos três sistemas de signos: o da informática, o das corporalidades e o do próprio jogo. Esses sistemas quando colocados em inter-relação produzem uma linguagem própria, organizada por códigos próprios. É nesse ponto que se estabelece a função criativa da linguagem. Sato (2009: 39) ao citar Gadamer para falar de obra de arte e jogo, indiretamente ajuda a explicitar essa questão.

(...) a obra de arte ganha seu verdadeiro ser ao se tornar uma experiência que transforma aquele que a experimenta. O sujeito da experiência da arte, o que fica e permanece, não é a subjetividade de quem a experimenta, mas a própria obra de arte. É justamente esse o ponto em que o modo de ser do jogo se torna significativo, pois o jogo tem uma natureza própria, independente da consciência daqueles que jogam.

As rupturas, transformações e criações nos códigos, nas linguagens e nos processos comunicacionais têm seu ambiente na fronteira da semiosfera e essa não pode ser compreendida como um espaço linear, mas como um conjunto de pontos que pertencem simultaneamente ao espaço interior e ao espaço exterior (Lotman, 1996). A fronteira funciona como um filtro, afeta e é afetada pelo exterior, mas elabora adaptações desses dois espaços. Não se pode desconsiderar, portanto, que a semiosfera dos jogos digitais contem regiões fronteiriças em que se constituem mesclas culturais e, assim, ambiências sígnicas. É nesse ambiente que se pode verificar as simetrias e as assimetrias, por outras palavras, as territorializações e desterritorializações de sentidos do jogo.

É próprio da semiosfera estar em constante inter-relação com o ambiente que lhe é externo pela mobilidade e penetrabilidade. Assim, são necessários contínuos processos de transformação pautados pela tradução para a construção da semiose. Para Lotman (2000) a relação assimétrica e a constante necessidade de escolha fazem da 


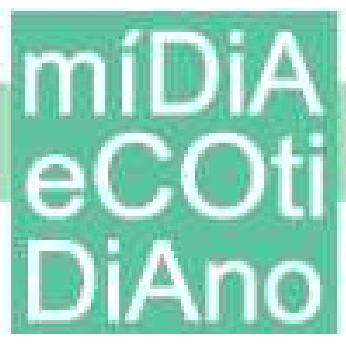

PPGMC

tradução um ato de geração de novos sentidos e corresponde à função criativa da linguagem e do texto. No caso em estudo, o papel da tradução é fundamental para o jogador e ela tende a se realizar com mais efetividade quanto mais conhecimento ele tiver dos códigos, linguagens e funcionamentos dos jogos. Contudo, ele precisa estar atento a todas as assimetrias encontradas, elas podem ser indícios preciosos para o jogo. A capacidade de tradução dos jogadores se correlacionada ao seu desempenho, bem como às habilidades desenvolvidas para (determinado tipo de) o jogo vai se refletir nas interações realizadas.

Primo (2007) entende que a interação é aquilo que existe "entre" os interagentes de uma ação (como jogar), seja ela de que tipo for. A imersão dos participantes no ambiente virtual (do jogo) se torna fundamental e pode ser facilitada pelo uso do mouse do computador, óculos 3D, também por canais de conversa (chat), ou por meio de imagens gráficas. Essas são usadas também para a composição dos avatares, representação do corpo humano, de personagens mitológicas e fantásticos e ainda outras formas, conforme o contexto do jogo.

O uso do jogo está vinculado ao conhecimento das linguagens e dos códigos colocados em movimento. Lotman (1978), afirma que: "Todo sistema que serve os fins da comunicação entre dois ou mais indivíduos pode ser definido como uma linguagem" (LOTMAN, 1978: 33). Neste sentido, ele propõe a linguagem como algo presente na cultura e constituída por mais de um código e com processos de construção dos sentidos ocorrendo pelo diálogo entre sistemas.

Machado (2008) apresenta o código como a condição da mensagem, pois é ele quem transforma e mensagem num conjunto de sinais prontos para serem lidos. $\mathrm{O}$ jogador digital encontra uma série de códigos que precisa decifrar e organizar no sistema do jogo. Ele precisa dominar aspectos da linguagem da máquina, seja pelo uso do console ou do teclado, seja pelo conjunto de regras e instruções que garantem a sua entrada no jogo. Contudo, ainda é preciso entender os códigos que se espalham pelo cenário do jogo e aqueles que são usados para interagir com os demais jogadores.

Quando se trata da construção de um avatar, é preciso dominar ou apreender vários outros códigos. A tradução gráfica do corpo do jogador implica num processo de 


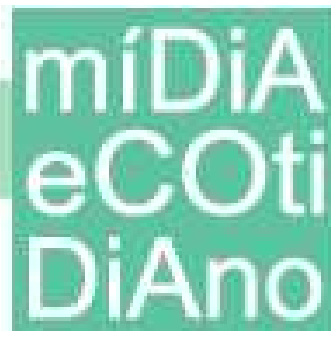

codificação (por meio do código gráfico) que não pode ser dissociado do processo de modelização do corpo.

De acordo Machado (2007), a tradução de sentido ocorre no processo de codificação-decodificação-recodificação do código. Assim, a compreensão do código se modifica e o indivíduo elabora outros conhecimentos sobre as imagens, os avatares, o aparelho e as formas de interação. Para o autor, diferente do que possa parecer - que no código não haja lugar para dicotomias - é possível admitir que diferenças coexistam. $\mathrm{O}$ código permite ser pensado como um sistema de probabilidades da ordem do imprevisível, pois nem todas as combinações possíveis no seu repertório de instruções são utilizadas, o que prevê possibilidades combinatórias em devir.

\section{O corpo avatar}

Entre as tantas possibilidades de novas formatações de pensamento, de comportamento, de interação trazida pelos jogos digitais, evidencia-se a configuração dos avatares ${ }^{8}$. Esses não se constituem como uma inovação total na ideia dos jogos, uma vez que a representação do humano sempre esteve presente, porém em outros formatos que assumiam outras materialidades. $\mathrm{O}$ que parece ter relevância no uso dos avatares em ambientes digitais é a sofisticação dessa representação em termos de detalhes e as múltiplas possibilidades de ação oferecidas ao jogador. Além disso, ele estabelece uma

\footnotetext{
${ }^{8}$ Conforme Fragoso e Rosário (2008), o significado e a origem do termo avatar já é de domínio comum. O termo vem do sânscrito e significa encarnação ou incorporação de um espírito numa forma material. Entre as lendas que contam a estória do avatar está a que o coloca como o meio material de comunicação entre os deuses e os terrestres. Assim, o avatar poderia existir em diversos mundos. Assim, a palavra 'avatar' não denota um corpo material como o nosso, mas a representação que carrega características divinas, independente das limitações de tempo e espaço com as quais nos confrontamos diariamente. Essa peculiaridade faz com que o conceito Hindu seja particularmente apropriado para denominá-lo, tendo em vista que os elementos do espaço digital funcionam como representações dos usuários humanos, tanto que a palavra se popularizou no mundo ocidental com esse significado. Em seus usos, o termo avatar inclui desde as mais simples representações, tais como o ponteiro que aparece na tela de acordo com a movimentação do mouse até as representações mais complexas, como as imagens gráficas refinadas dos caracteres em jogos de computador.
} 


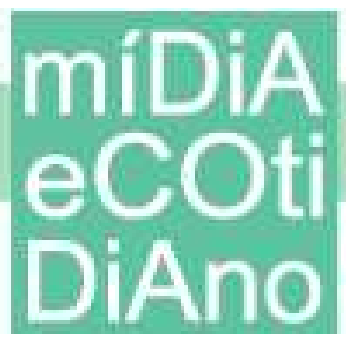

PPGMC

relação íntima entre o orgânico e o digital, que se potencializa pela proposta do jogo simular, fantasiar. É a inscrição do vivo no não-vivo como afirma Babo (2004).

O avatar no jogo digital multimídia torna-se o principal meio de expressão do corpo do jogador por meio de imagens em movimento; também representa o indivíduo simbolicamente como extensão de seu corpo para o espaço virtual, porque vem a ser primordial para a interação mediada por computador. A representação gráfica do corpo do jogador, embora não seja a cópia perfeita do seu corpo, com suas limitações e habilidade motoras, instaura sentidos de mobilidade, coordenação motora, agilidade, ritmo, memória visual e noção espacial próprios da cultura.

A interatividade e os detalhes gráficos envolvidos na configuração do avatar através das ferramentas da informática são fatores importantes na complexidade de relações forjadas entre o sujeito e o seu avatar. É importante lembrar, contudo, que a realidade do avatar se impõe por meio de sua história como mediador nas interações entre a temática de que se reveste e os povos (que são igualmente representados por avatares) em ambientes digitais compartilhados. Essa representação do jogador em imagem tem uma imaterialidade natural, a qual livra o sujeito das limitações do seu corpo e das limitações do tempo e do espaço físico devido à necessidade de haver a criação especificamente para aquilo ou aquele que representa (FRAGOSO e ROSÁRIO, 2008).

No jogo digital que requer a construção de um avatar há um padrão de modelização do corpo, com movimentos instituídos pelo software do jogo e limitados pelas opções de configuração do corpo digital. $\mathrm{O}$ avatar se utiliza tanto da linguagem verbal (na maioria das vezes por meio de chats), quanto da linguagem corporal (organizada sobre uma estruturalidade) para estabelecer seus processos de interação e de conquista de pontos no jogo. Essas linguagens podem ser pensadas a partir de um princípio organizador. Para Iuri Lotman e Bóris A.Uspênski, conforme apresenta Machado (2007), "a linguagem verbal se confirma como sistema dotado da estrutura de que fala Jakobson, enquanto as outras linguagens da cultura só podem ser pensadas teoricamente a partir de uma estruturalidade, com a conotação de um princípio 


\section{míiA

organizador, que não chega a ser estrutura, mas mostra uma organização do sistema" (MACHADO, 2007: 28).

É importante lembrar que os semioticistas da cultura afirmam que a linguagem é um sistema de comunicação, tanto quanto um sistema modelizante e ambas as funções se implicam mutuamente. Assim, eles denominaram os "sistemas modelizantes" em dois tipos: primário e secundário. A linguagem verbal é considerada como sistema modelizante primário, por ser dotada de uma estrutura referencial que permite a seleção, o arranjo e a combinação de configurações sígnicas comunicantes, na qual se reconhece num dado sistema, sua estrutura. Os outros sistemas da cultura são definidos como sistemas modelizantes secundários, por serem constituídos por uma estruturalidade e não por uma estrutura.

Os avatares em jogos digitais configuram-se, sobretudo, pelos sistemas modelizantes secundários, mas claro que contam também com o primário. $\mathrm{O}$ sistema modelizante secundário nos interessa especialmente por ser o ambiente da semiótica da cultura. No campo da cultura a modelização passa a designar processos de regulação de comportamento dos signos para constituir sistemas, visto que funciona como um programa para a análise e constituição de arranjos. A modelização permite a existência de configurações sígnicas particulares, específicas e ao mesmo tempo comunicantes, coexistindo numa cadeia de linguagens, permitindo a compreensão de seus significados. O relacionamento dinâmico entre os sistemas da cultura foi definido como um processo de modelização, segundo o qual a cultura é entendida como texto e a comunicação, como processo semiótico.

Nos jogos digitais o corpo físico do jogador se representa num corpo virtual que se difere do original de muitas maneiras, mas uma delas é, sem dúvidas, a ausência de órgãos, ou o corpo oco, conforme menciona Le Breton (2004) e evidencia Stelarc (1997: 56): “A solução para modificá-lo não pode ser encontrada em sua estrutura interna, ela está simplesmente em sua superfície". Se, por um lado, a representação da pele é um dos elementos essenciais para a incorporação do avatar, por outro, a pele do jogador perde sua função de fronteira/limite do corpo, já que o sujeito passa a existir em, pelo menos, dois mundos, transpondo limites. A noção de corpo cujas fronteiras 


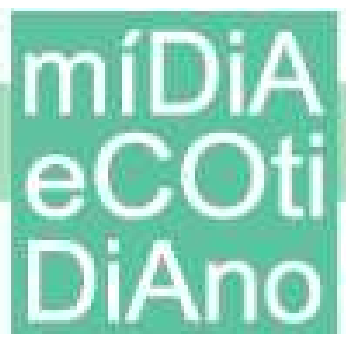

PPGMC

estão nos limites da pele sofre reconfiguração. É possível existir além e aquém da pele (ROSÁRIO e RAMOS, 2006).

A criação do avatar possibilita aos usuários a utilização de diferentes configurações de gêneros, etnias, estéticas, sexualidades, construindo este corpo virtual com personalidades híbridas e/ou fragmentadas, que podem ser constantemente reconstruídas. "Se antes o corpo encarnava o destino da pessoa, a sua identidade intangível, hoje é uma proposição a afirmar e a restaurar permanentemente. Entre o homem e o seu corpo tem lugar um jogo, no duplo sentido da palavra”. (LE BRETON, 2004: 67).

É fato que o jogador cria e codifica o avatar, de acordo com as opções dadas pelo jogo, para representa-lo, para assumir a ficcionalidade do jogo, para permitir sua ação. O avatar é o mediador do jogador, torna-se uma forma de vida que habita os ambientes digitais, podendo assumir os mais diversos formatos. É esse aspecto (o formato) que aparece como relevante em alguns jogos digitais em que os jogadores, ao construírem seus avatares, mostram que estão atrelados à modelização do sistema do corpo na cultura ocidental. A pesquisa realizada por Fragoso e Rosário ${ }^{9}$ aponta que, apesar das tantas possibilidades de criação de seres e objetos oferecidas pela máquina (mesmo que limitadas pelas opções disponíveis), os jogadores se atinham a construir seu avatar de forma similar a si mesmo e de acordo com a estética caucasiana. Contudo, esse mesmo tipo de jogo oferece pela simulação uma ilusão de divino: o jogador dá forma e 'vida' a famílias, bairros, cidades inteiras, em por exemplo The Sims, Second Life, Sim City, Rooler Coaster Tycoon.

Os traços do corpo avatar constroem, assim, uma extensão das identidades que habitam o jogador e que mostra parte do que eles são. O processo de criação do boneco digital passa, inevitavelmente, pelas representações de sujeitos existentes nos mundos habitados pelo interator, o que remete em grande parte aos estereótipos construídos, as convenções e aos ideais que moldam o imaginário do sujeito.

\footnotetext{
${ }^{9}$ Para saber mais: FRAGOSO e ROSÁRIO, 2008.
} 


\section{míDiA
eCOti
DiAno}

\section{Considerações Finais}

Pode-se perceber que, na semiosfera do jogo, alguns mecanismos foram reconfigurados para sua versão digital, tais como modos de jogar, lugar de realização, formas de interação entre jogadores, modos de simulação. Todavia, outros mecanismos permaneceram, como o lúdico, o divertimento, o mistério. Ainda mais, os sistemas modelizantes articularam regularidades, mas a cultura e a semiosfera propiciam irregularidades e desterritorializações, fazendo com que entrem em correlação os sistemas da informática, das corporalidades, das histórias fantásticas, entre outros.

O jogo digital apresenta uma reconfiguração considerável da cultura do jogo. Aquele tem seu eixo de sustentação na tecnologia e na cibercultura, seus códigos se remodelam assumindo uma complexidade própria, suas narrativas retomam, muitas vezes, tempos passados, seus mecanismos se reorganizaram, mas a diversão e o lúdico se mantem como essência de qualquer jogo.

Entre os jogos estudados ${ }^{10}$, as categorias que mais se evidenciam são Agon e Mimicry, reunindo dois tipos de jogos que não têm muitas correlações previstas por Caillois (1990). Entre as combinações de categorias propostas pelo autor, as que têm mais força na cultura são, por um lado, Agon e Alea e, por outro, Mimicry e Ilinx. A primeira delas perpassa diversos âmbitos das relações dos sujeitos, desde os profissionais até os pessoais e, muitas vezes, conduz às relações afetivas. Essa combinação, entretanto, por suas características, tende a restringir a vida ao mérito e/ou à sorte e, por isso mesmo, reflete uma dualidade de opções - a qual retrata, também, a dualidade da sociedade (moderna) nos últimos séculos. O segundo tipo de combinação Mimicry e Ilinx-, para Caillois (1990), é o que explica melhor os mecanismos da própria cultura, entretanto, tende a ser renegado nas sociedades que se dizem civilizadas e estão aliadas ao progresso e à razão.

A articulação de Agon e Mimicry, que se estabelece nos jogos digitais, reorganiza os elementos que adquirirem força no âmbito da cultura e do social

\footnotetext{
${ }^{10}$ The Sims, Second Life, Sim City, Rooler Coaster Tycoon, Resident Evil, Michael Jackson- The Experience, Fottball; Guitar Hero; Central Dance, World of war craft, God of War.
} 


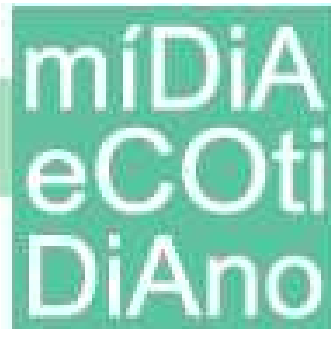

evidenciando o mérito, a inteligência (Agon), o imaginário e a simulação (Mimicry). Se na visão de Caillois (1990) essas são categorias que não se combinam facilmente, é possível vislumbrar um cenário diferenciado para o jogo digital. Esse constrói conexões entre aspectos predominantes no mundo moderno (lógica, razão e ordem), com aspectos das sociedades contemporâneas (simulação, ilusão e afetual). A atividade lúdica precisa contar com a inteligência do jogador, mas permite que a força física atue de forma delegada pelo avatar (Agon), também precisa que a racionalidade seda lugar à fantasia para penetrar na ficção e na subjetividade do imaginário (Mimicry).

\section{REFERÊNCIAS:}

BABO, Maria Augusta. Do corpo protésico ao corpo híbrido. Revista de Comunicação e linguagens - Corpo, técnica, subjetividade. N.33, jan/2004. p.25-35.

BAKHTIN, Mikhail. Estética da Criação Verbal. Tradução de Maria Ermantina Galvão G. Pereira. $2^{a}$ edição. São Paulo: Martins Fontes, 1997.

CAILLOIS, Roger. Os jogos e os homens - a máscara e a vertigem. Lisboa: Cotovia, 1990.

FRAGOSO, Suely e ROSÁRIO, Nísia Martins. Just like me only better. In: Cultural attitudes towards technology and communication. Murdoch: Murdoch University, 2008, v. 1, p. 314327.

HUIZINGA, Johan. Homo Ludens: o jogo como elemento da cultura. São Paulo: Perspectiva, 2010.

HUIZINGA, Johan. Homo Ludens: o jogo como elemento da cultura. São Paulo: Perspectiva, 1996.

LE BRETON, David. O corpo enquanto acessório da presença - notas sobre a obsolecência do homem. Revista de Comunicação e linguagens - Corpo, técnica, subjetividade. N.33, jan/2004. p. $67-81$.

LOTMAN, Iuri. A Estrutura do Texto Artístico. Tradução de Maria do Carmo Vieira Raposo e Alberto Raposo. Lisboa: Editorial Estampa, 1978.

Cultura y Explosion. Lo Previsible y lo Imprevisible en los Procesos de

Cambio Social. Tradução de Delfina Muschietti. 1ª edição. Barcelona: Editorial Gedisa, 1996. 


\section{eco DiAno}

La Semiosfera III. Semiótica de las Artes y de la Cultura. Tradução e seleção de Desiderio Navarro. Madrid: Edicones Frónesis Cátedra Universitat de València, 2000 .

MACHADO, Irene. Escola de Semiótica: A Experiência de Tártu-Moscou para o Estudo da Cultura. São Paulo: Ateliê Editorial, 2003.

(org). Semiótica da Cultura e Semiosfera. São Paulo, Annablume, 2007.

O filme que Saussure não viu: o pensamento semiótico de Roman Jakobson. Vinhedo, Horizonte, 2008.

MAFFESOLI, Michel. No fundo das aparências. Petrópolis: Vozes, 1999.

PRIMO, Alex. Interação mediada por computador: comunicação, cibercultura, cognição. Porto Alegre: $2^{\mathrm{a}}$. Edição, Sulina, 2008.

p. 1-21, 2007.

O aspecto relacional das interações na Web 2.0. E- Compós (Brasília), v. 9,

ROSÁRIO, Nísia Martins e RAMOS, Mariana. Encarnações lúdicas no ciberespaço. Razón y Palabra, v. 52, p. 158-171, 2006.

SANTAELLA, Lucia e FEITOZA, Mirna (Orgs). Mapa do jogo. São Paulo: Cengage Learning, 2009.

SATO, Adriana K. O. Design e ressignificação do imaginário no jogo. In: Anais do $\mathbf{8}^{\mathbf{o}}$ Congresso Brasileiro de Pesquisa e Desenvolvimento em Design. P\&D/Design/8. São Paulo: Centro Universitário Senac, 2008.

STELARC. Das estratégias psicológicas às ciberestratégias; a protética, a robótica e a existência remota. In: DOMINGUES, Diana (org.). A arte no século XXI: a humanização das tecnologias. São Paulo: Editora da Unesp, 1997.

VELHO, Ana Paula Machado. A Semiótica da Cultura: apontamentos para uma metodologia de análise da comunicação. In.: Revista Estudos em Comunicação. Curitiba, v. 10, n. 23, p. 249-257, set/dez. 2009 